Market prices of remanufactured, used and new items: evidence from eBay

João Quariguasi Frota Neto (corresponding author)

University of Bath, School of Management.

Contact: Wessex House, room 9.10, Bath, United Kingdom, e-mail:

jqfn20@bath.ac.uk, telephone: +44 (0) 1225383886

Jacqueline Bloemhof,

Wegeningen University, Logistics, Decision and Information Sciences.

Contact: Leeuwenborch, 6th floor, room 6015, Wageningen, The Netherlands, e-mail: jacqueline.bloemhof@wur.nl, telephone:+31 (0)317 - 484726.

\title{
Charles Corbett
}

University of California at Los Angeles (UCLA), Anderson School of Management. Contact: Gold Hall, Suite B-507, 110 Westwood Plaza, Los Angeles, California, e-mail: charles.corbett@anderson.ucla.edu, telephone: +1 (310) 825-1651.

Keywords: remanufacturing, sustainable supply chains, reverse logistics, willingness-to-pay, information asymmetry. 
1 2 3

\title{
Market prices of remanufactured, used and new items: evidence from eBay
}

\begin{abstract}
Extending the life-cycle of products has received ample attention in the field of reverse logistics, but research on the market acceptance of remanufactured products is still in its infancy, especially how they compare to used products. In this paper, we investigate how consumers perceive remanufactured products relative to used and new products. We construct a database containing 1,716 eBay listings, and use that to investigate the factors that influence the differences in prices between used, remanufactured, and new iPods. Our results confirm that remanufactured products are sold at a discount relative to new products. New to the literature on reverse logistics are the following results. For all types of iPods we find evidence that remanufactured products command a premium over their used counterparts. Also, for two types of iPod, a positive description of the product increases the average price for used products relative to remanufactured ones, which suggests that consumers need less reassurance regarding the quality of remanufactured products than used ones. Furthermore, for the third type of iPod, and for all new and remanufactured products, we find no evidence that a positive description significantly affects price. We explain our findings through the lenses of information asymmetry and adverse selection. We also observed that price dispersion is higher for used than for remanufactured products, indicating that remanufacturing may homogenise the quality of products, or at least the way consumers perceive them. We conclude that consumer perception of remanufactured products relative to their used and new counterparts, and hence their willingness to pay, depends in subtle and not yet well-understood ways on the nature of the product.
\end{abstract}

Keywords: remanufacturing, sustainable supply chains, reverse logistics, willingness-to-pay, information asymmetry. 


\section{Introduction}

For many years, a myriad of different products have been returned to be re-processed and put back into the market. Cameras, car parts, mobile phones, MP3 players, PCs, photocopy machines and power tools are some examples (Apple Computers 2007a, Fleischmann et al. 2003, HP 2009, Kerr and Ryan 2001, Ketzenberg et al. 2003, Krikke et al. 1999, Li et al. 2009, Savaskan et al. 2004, Tang and Teunter 2007, González-Torre et al. 2010, Van Wassenhove and Zikopoulos 2010, Chan et al., 2012). Returned products must be collected, tested and repaired, and sometimes upgraded before they are returned to the market as refurbished, remanufactured or reconditioned. (In this paper, following existing literature, such as Blackburn et al. (2014), we do not make a distinction between refurbished and remanufactured products.) In other words, it is not possible for us to ascertain in this paper that the products that are sold as remanufactured in our dataset are of exactly the same functional and cosmetic conditions as new ones.

Although some products that have undergone a process of cleaning and repairing are equivalent to new ones (Thierry et al., 1995, p. 119), research indicates that consumers may not perceive them as such (Guide and Li 2010, Quariguasi Frota Neto 2008, Subramanian and Subramanyam 2012).

In this paper, we shed more light on consumers' perceptions of used, remanufactured, and new products by examining differences in the Willingness-to-Pay (WTP) for these three product conditions. (From here on we refer to used, remanufactured and new as "product conditions".) Our study addresses the following two research questions: First, how much are consumers willing to pay for remanufactured products relative to used and new ones? Second, do cues about the product's quality provided by the seller have a differential impact on consumer WTP for these three product conditions? The comparison of remanufactured vs. new has been studied previously. The 
contribution of our work lies in the comparison with used products, and in exploring the role of cues about product quality on these comparisons.

To empirically investigate the differences in prices between used, remanufactured, and new products, we create a dataset containing 1,716 real transactions of three models (Classic, Touch and Nano) of used, remanufactured, and new iPods sold on eBay. We confirm that remanufactured products are purchased at a discount compared to new ones, keeping all else constant. We also find that for all three iPod types, remanufactured products are purchased at a premium compared to used ones. These findings are relevant to corporate decisions concerning whether to re-sell, remanufacture, or dispose of end-of-life products, as we further elaborate later (Debo et al. 2005, Galbreth and Blackburn 2006, Inderfurth 2004, Klaus and Hendri 2000, Parlikad and MacFarlane 2007).

We also find that for two of the three product types, textual quality cues have significantly less effect on consumer WTP for remanufactured iPods than on that for used ones. We draw on the theories of asymmetry of information and adverse selection to explain that difference. The effects of a visual quality cue, the number of pictures shown in each of the listing, are rather inconclusive.

The rest of this paper is organized as follows. In Section 2, we review relevant literature and outline our hypotheses. In Section 3, we describe the data collection method and research methodology. In Section 4 we report our empirical results. In Section 5 we discuss the main results of our analysis. In Section 6, we summarize the conclusions of this paper, its limitations, and propose avenues for further research. 


\section{Hypotheses and Related Literature}

Our first objective is to compare the magnitude of consumer WTP for remanufactured relative to new and used product conditions. Our second objective is to examine whether information asymmetry about product quality has a differential impact on consumer WTP for used, remanufactured, and new product conditions. In this section we outline our hypotheses and briefly describe the related literature.

\subsection{How do consumers perceive remanufactured products relative to new and used products?}

Although the literature on remanufacturing has bloomed, there has been relatively little empirical work carried out in this field (Atasu et al. 2008, Prahinskia and Kocabasoglub 2006, Rubio et al. 2008). In particular, articles that study the demand side are few. Most research on reverse logistics makes assumptions on consumers' WTP and consequently on the relationships between prices and sales volumes of new and remanufactured items, e.g. Debo et al. (2005) and Ferrer and Swaminathan (2006). Although some of these assumptions are plausible, e.g. that the WTP for remanufactured items is lower than that for new ones, they are not yet based on systematic empirical research.

Among the few empirical studies in this area, Guide and Li (2010), using field experiments consisting of auctions of power tools and computer systems, investigate the cannibalization that remanufactured products may cause. Their evidence indicates that there is a significant difference in consumers' WTP for remanufactured and new items for both consumer and commercial products. Using data from a controlled experiment with university students, Quariguasi Frota Neto (2008) finds that the price of a new product affects the WTP for its remanufactured counterpart, and that 
remanufactured products are sold at lower prices than otherwise similar new products. Subramanian and Subramanyam (2012) exploit data on prices of remanufactured and new products collected from eBay and online stores, and also obtain evidence that consumers prefer new over remanufactured products. Ovchinnikov (2009) surveys students to find that the WTP for remanufactured products is influenced by the sales price of their new counterparts. Agrawal et al. (2010), in turn, show that the existence of a remanufactured product line affects the WTP for their new counterparts, and that such effect is different if the OEM or an independent remanufacturer introduces the line. Abbey et al. (2014) use experiments to find that, among others, consumers are more attracted to a remanufactured product if it carries a greater discount relative to a new product. Hazen et al. (2012) show that consumers with greater levels of ambiguity tolerance are willing to pay higher prices for remanufactured products, and that this effect is moderated by perceived product quality. We refer to Section 3.5 in Agrawal and Toktay (2009) for an extensive literature review on this topic. Our first hypothesis continues this early focus on the difference between remanufactured and new products; although not novel in itself, it serves to replicate the findings of prior research:

H1. Selling prices of new products are, ceteris paribus, higher than those of remanufactured products.

One of our contributions lies in examining the difference in consumer WTP between remanufactured and used product conditions. Akerlof (1970) highlighted the information asymmetry that exists when selling used products. Remanufacturing a used product is a way to reduce the variance in quality of used products, and hence could help to mitigate that information asymmetry as long as buyers perceive remanufacturing as having that effect. We believe that "remanufacturing" conjures up associations with terms like "inspection", "by company", "quality control" and, in the 

we found examples of buyers complaining on online forums that they have received their remanufactured iPods with small scratches, while they expected to receive like-new products. On the same forums, we found that keywords like "testing" and "tested" appeared frequently. Given the improved functional and cosmetic quality of remanufactured relative to used products, we expect remanufactured products to elicit a higher consumer WTP than used items.

Labelling an item as "remanufactured" might have two opposing effects on the final price paid for the item. On the one hand, consumers may be reassured that that they are getting a product that has been inspected, restored to essentially to the same conditions as a new product, and tested. For electronic items, for instance, it may indicate that batteries or malfunctioning screens have been replaced. Moreover, consumers may believe that remanufactured products are more homogeneous in quality than used products, and in particular that there is less downside risk associated with remanufactured products. Buyers' natural loss aversion would then render remanufactured products more attractive than their used counterparts due to their lower variability in quality, creating a premium for the former, even if average quality of the two conditions were similar (Kahneman and Tversky, 1979). On the other hand, consumers may be concerned that a product labelled as "remanufactured" must have been damaged, as otherwise it could have been simply resold as-is rather than requiring remanufacturing. Products with moving parts (e.g., engines) are subject to gradual wear and tear; remanufacturing might be seen as a desirable way to restore such products to as-new conditions. Products with no moving parts (e.g. some electronics) do not experience gradual wear and tear; it either works or it is physically broken. For such a product to be labelled "remanufactured", consumers might assume that it must have been broken, as otherwise there would have been no point in remanufacturing it. For many products, both effects may exist side-byside; however, the information asymmetry associated with used products is well-documented, while 
the potential negative inference associated with remanufacturing is speculative. We thus obtain the following hypothesis:

H2. Selling prices of remanufactured products are, ceteris paribus, higher than those of used products.

Next, we develop hypotheses related to additional factors that may mitigate this information asymmetry.

\subsection{Information asymmetry and quality signalling in the markets of used, remanufactured} and new products

Our second objective is to measure the differential impact of adverse selection on consumer willingness to pay for used, remanufactured, and new products. The adverse effect of information asymmetry on the functioning of markets was first formalized in the seminal paper of Akerlof (1970), in the context of the second-hand car market. Akerlof states that sellers have no incentive to sell high-quality second-hand cars when buyers cannot perfectly observe the quality of the cars before purchase, and as a result good sellers are pushed out of the market, which then is eventually dominated by low quality products and sellers.

Literature has suggested that the problem of information asymmetry is magnified in electronic markets such as eBay (Lee at al. 2000), as buyers do not have the opportunity to try out the product before purchase or, as Resnick et al. (2006) put it, to "squeeze the orange". Furthermore, consumers cannot rely on some of the quality cues commonly found in the brick-and- 
mortar environment, as those provided by the quality of presentation in the shop where the products are sold.

The fact that online markets have not died out, despite these inherent disadvantages, shows that consumers, sellers, and online market platforms have found ways to signal and assess the quality of products and sellers without actually seeing them, quality being a chief source of competitive advantage for sellers (Morgan and Piercy, 1996). Literature tells us that consumers use a plethora of these signals when shopping online, e.g., advertisements (Milgrom and Roberts 1986, Wiggins and Lane 1983), brand names (Doods et al. 1991), country of origin (Miyazakiet et al. 2005), credit ratings (Akerlof 1976), seller's reputation (Lucking-Reiley et al. 2007, Melnik and Alm 2002, Resnick et al. 2006), graphical representations (Koppius et al. 2004, Ramachandran et al. 2008), prices (Dawar and Parker 1994, Farrell 1980, Milgrom and Roberts 1986), product reviews (Ramachandran et al. 2008), and warranties (Boulding and Kirmani 1993, Srivastava and Mitra 1998).

We indirectly assess the magnitude of the adverse selection problem for used, remanufactured, and new products by measuring the effect of quality cues on consumer WTP for these three product conditions. Specifically, we investigate how a textual product description and the number of pictures displayed in a listing affect the WTP for used, remanufactured and new products. We expect information asymmetry about product quality to be more severe for remanufactured than for new products, due to the uncertainties associated with remanufacturing. We also expect information asymmetry to be more severe for used than for remanufactured products, since the former lack the additional manufacturing testing and quality checks of the latter. We predict that more severe information asymmetry increases consumers' need for additional information on the product, translating into a stronger impact of quality cues on consumer WTP. We thus obtain the following predictions on the relative impact of quality cues on the three product conditions: 

cues than those of new products.

H4. Selling prices of remanufactured products are, ceteris paribus, less affected by quality cues than those of used products.

The extent to which textual descriptions affect consumer WTP and sales volumes has been previously studied in the context of seller feedback (Ghose et al. 2007) and product reviews (Archak et al. 2011). While these studies focus on descriptions of the quality of the seller (seller feedback), we explore the effect on consumer WTP of a textual cue for the quality of the product.

Prior research has also examined the effect of visual representations of the product on WTP (Koppius et al. 2004, Lewis 2007). Koppius et al. (2004) examined the Dutch flower market and found that visual representation (positively) affects WTP. Lewis (2007) found evidence of a similar effect on second-hand cars sold on eBay.

Seller feedback is less relevant for our research than product-specific quality cues. There is no clear reason why consumer feedback associated with a seller would have a different effect on our three product conditions (new, remanufactured, used). Arguably, a seller with favourable feedback regarding, for example, delivery timeliness might be able to command higher prices than a not-soreputable seller. However, we believe that this positive effect should apply equally to all product conditions. We therefore consider seller feedback only as a control variable, and focus on the hypothesized differential effect of product-specific quality cues on consumer WTP for used, remanufactured, and new products. 


\section{Data Collection and Methodology}

We first motivate why we focus our analysis on iPods. We then describe how we construct the samples of iPods used in our analysis. We then discuss the control variables included in our regressions and provide descriptive statistics.

\subsection{Why iPods?}

Auctions are commonly used in scholarly work to elicit WTP. Ariely et al. (2005), Muller and Mestelman (1994), and Resnick et al. (2006), for instance, emulate real auctions in laboratory settings to measure consumer W'TP. Guide and Li (2010), Harrison and List (2004), Katkar and Reiley 

(2002), Lucking-Reiley et al. (2007), and Subramanian and Subramanyam (2012) use secondary data collected from completed electronic auctions to estimate WTP.

By contrast, we proxy consumer WTP by studying selling prices of iPods on eBay. The first iPod was launched in October 2001 by Apple Computers. iPod is by far the most popular brand of MP3-players, with a market share of $72.3 \%$ as of 2007 . More than 100 million units had been sold worldwide as of 2007 (Apple Computers 2007b, Bloomberg 2007). We focus our analysis on iPods for three main reasons. First, the product is very homogeneous, which reduces the number of control variables required in our analysis (Eaton 2005). Second, iPods are among the most traded items on eBay. This frequent trading allows us to obtain a large number of observations for used, remanufactured, and new items sold at approximately the same time. iPods are sold in five models: Classic, Mini, Shuffle, Touch, and Nano (Table 1). The iPod Classic is the original Apple MP3 player. It consists of a small hard drive, an LCD display, and a "click wheel" for users to scroll through and select from the music selection shown on the display. The iPod Mini is a smaller version of the iPod Classic but with the same components. The iPod Shuffle is comparable to the iPod Mini, but is much smaller, and has less memory. The iPod Touch is the first iPod without moving parts (other than an on-off switch). It has a touch screen instead of the click wheel, and it uses flash memory rather than a hard drive. The iPod Nano is even smaller than the iPod Mini. Similar to the iPod Touch it uses flash memory, but the first five generations of iPod Nano (including all those in our data) do still have a click wheel. (See http:/ / support.apple.com/kb/ht1353 for a summary of different types of iPods.)

A third reason why iPods are particularly suitable for our research purpose is that they are commonly sold in used, remanufactured, and new conditions. eBay clearly outlines the product condition of each auctioned iPod. Used iPods are sold in large numbers on eBay, and traded by both 
individuals and companies. These are products in working condition that have not been repaired and have mostly not been tested. Remanufactured iPods, in turn, are frequently sold, usually by independent remanufacturers rather than by individuals. Although Apple does sell remanufactured iPods, it virtually never uses eBay for this purpose. iPods are remanufactured for two main reasons: first, when items are returned for repair, in which case they are remanufactured and redirected to the secondary market, and second, when items in perfect condition are returned to the seller. Such items, which are often in "like-new" condition, only need to be tested to be sold as remanufactured (Ferguson and Toktay 2006). These returns are called commercial returns, and the receiving end is the Original Equipment Manufacturer (OEM), e.g. Apple in the case of returned iPods. The category "new" refers to brand new products manufactured by the OEM.

\section{(INCLUDE TABLE 1 HERE)}

We constructed our sample of used, remanufactured, and new iPods in the following way. In a first step, we used a software agent and started from a sample of 4,700 observations of iPods advertised on eBay from June to August 2009. More specifically, iPod Classic data were collected in August, Nano data were collected in July, and Touch data were collected in June of the same year. The agent focused on the three (at that time) most popular types of iPods: Classic, Touch and Nano.

We programmed the software agent to retrieve all text visible to the buyer, i.e., not only the data contained in the HTML files that generates the listings, but also the text contained in all files linked to them, e.g. other HTML files, pictures, etc. that can be accessed by clicking on the first file. Some past studies have used only the first HTML file (e.g., Heijst et al. 2008), or parts of this file. However, a careful analysis of the files reveals that a host of important data would be lost had we not collected the data from these auxiliary files. This was particularly true for listings of iPods sold 
by independent companies, who are more likely to use dynamic resources compared with consumers. Ignoring this data would therefore bias the results.

In a second step, the relevant data were parsed, meaning that for each listing, all text visible to the buyer is included in a single text file. Subsequently, items sold as "buy it now" and items not sold were eliminated from the sample.

After these automated steps, we manually selected and checked the data for accuracy. For each observation, we compared the data obtained by the agent with the raw data from the eBay listings for potential errors and empty fields. We detected virtually no errors in the data in cases where the software agent had to simply collect the value of a variable (e.g., number of positive consumer feedbacks for a given seller). However, we uncovered various errors and omissions in cases requiring some level of interpretation from the software agent (e.g. determining the existence of a warranty or the presence of a major defect in the product), which we then manually corrected. We manually eliminated listings of products that were defective or sold for spare parts, did not belong to the categories of products being investigated (e.g. iPod copycats), were sold in a currency other than U.S. dollars, were sold to a buyer outside the United States, or had other special characteristics, e.g. products that have been autographed by celebrities. We than sampled remaining observations and create a set with 1,716 observations, roughly equally distributed among the three product types: 632, 541 and 543 observations of, respectively, iPods Classic, Touch and Nano.

\subsection{Variables}

In this section we describe the variables used in this paper. For each traded iPod, we collect the following information: selling price, number of positive keywords found in the listing, number of pictures of the product in the listing, product condition (i.e. used, remanufactured, new), number of 

used to capture the presence of a favourable product description contained in the listings is obtained by simply counting the number of times a keyword or sentence indicating a high cosmetic or functional quality level is mentioned in the listing, e.g. "mint" and "brand new". Table 2 shows examples of favourable descriptions. These keywords were obtained from a sample of 50 iPod listings that were not included in the main sample used for the analyses. The selection of the keywords was initially carried out by two coders (individuals who are not co-authors of the current paper). The coding was then thoroughly checked for consistency by one of the authors of this paper. We noted that a number of the keywords chosen kept recurring over different listings, which suggests that this list captured most of the positive descriptions. The final list is the union of the two lists. We call the number of positive keywords contained in a given listing POSKEYWORD.

Inevitably, the list of keywords we used to define POSKEYWORD is not complete, and the degree to which any other keyword affects consumer perception will vary from keyword to keyword. We cannot measure consumers' perception of an entire product description directly from our data, but as long as the measurement error between this unobservable perception variable and our POSKEYWORD proxy is not correlated with the difference in price between used, remanufactured and new items, this is not a concern.

Another quality cue examined in this paper is the number of pictures of the product shown in a given listing, which is labelled as ORIGINAL.PICTURE. 


\section{(INCLUDE TABLE 2 HERE)}

We also classified each item as used, remanufactured or new following the classification provided by the seller. In case the seller did not provide this information in a way our software agent recognized, we checked the listing and classified the product ourselves, based on the description of the product (variable CONDITION).

We used the sellers' negative and positive feedbacks received in the last 90 days as a control variable. Ratings on eBay work as follows. Buyers and sellers rate each other, and the feedback is registered in three forms: the content of each feedback in the form of a text, the number of positive and negative feedbacks received, and the proportion of negative to positive feedbacks. In line with past research, we use the absolute number of positive and negative feedbacks as our measure of seller's quality (Lucking-Reiley et al. 2007, Melnik and Alm 2002), which we designate as POSFEEDBACK and NEGFEEDBACK, respectively.

In addition, we controlled for other key characteristics of the products, namely memory and generation (variables MEMORY and GENERATION). Generation captures both age and features of the products. We also control for shipping costs and handling charges (variable SHIP). To calculate these costs, we consider the cheapest shipping alternative (but exclude the option to pick up the product). We calculate all shipping costs using the address of one of the authors, who is located in the United States. Using this address or any other should not change our results for the following reasons. First, the vast majority, i.e. $94 \%$ of all of the listings, do not require such calculation, either because one shipping price applies for the entire country or because the listing offers a free shipping policy. Second, shipping prices are, in most cases, substantially lower than the final price of the product, i.e. less than $5 \%$ for each of the iPods. Third, we have no reason to 
believe that these differences in shipping prices are in any way correlated with the condition of the product (i.e. used, remanufactured and new).

We initially also controlled for warranties provided by the seller and the OEM. We registered any warranty offered that is 30 days or longer because we believe that a buyer will not consider shorter warranties to be very meaningful. Warranties covering less than 30 days are rare, so ignoring or including them would not make much difference. The most common warranty periods are for 30 , 60 or 90 days, and in very few cases warranties are extended for more than 90 days. Warranties provided by the OEM are, on the other hand, almost invariably for one year, but for used products part of this warranty has already expired. In this case, we consider a product to be covered by an original warranty if there are at least 30 days of original warranty left (e.g., a product with a one-year warranty that was first purchased less than 11 months ago). We did not include warranties in our final analysis, however, because few listings offered products with warranty, and even fewer products with original warranty. Note, however, that the results are robust to the inclusion of these variables.

\section{Analysis}

In this section we present our analysis and empirical results. We estimate the following equation separately for each type of product (Classic, Touch, and Nano).

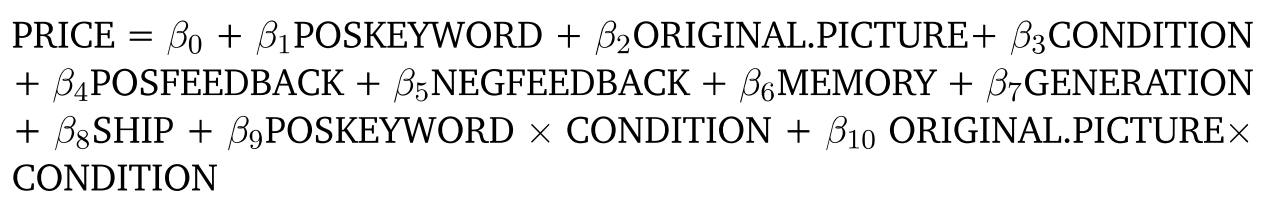

This regression is used to test hypotheses $1,2,3$ and 4 . The analyses were carried out in $R$ Statistical Computing. The model parameters were initially estimated using OLS. We eliminated all 
observations with studentized residuals greater than 3. The number of such outliers was very small, less than $2 \%$ of observations in the sample for each of the product types.

To assess the suitability of OLS, we tested for the presence of multicollinearity and heteroscedasticity. To test for multicollinearity, we first analysed the correlations between independent variables for the three types of iPods. We found for all three models that the independent variables exhibit low correlation, with one notable exception, the pair POSFEEDBACK and NEGFEEDBACK. We used the Variance Inflation Factor (VIF) test for all three iPod models (Classic, Touch and Nano), which showed that VIFs were mostly below the suggested limit of 10, with the exception of iPod Touch, which presented in one case a VIF of 1,400 (Ranaweera and Neely 2003, Neter et al. 1995), caused by the correlation between positive and negative feedbacks. Suppressing these variables from the regression eliminates collinearity, without changing any of our main results. In summary, our results are not significantly affected by collinearity.

The Breusch-Pagan test indicated heteroscedasticity for the iPod Classic ( $\chi$-square of 89.64), Touch $(\chi$-square of 40.44$)$, and iPod Nano ( $\chi$-square of 232.7$)$, but in all cases, calculating the tvalues using White's heteroscedasticity consistent standard errors (White 1980), we obtained results that were similar to those of the OLS model. In summary, our results are affected by neither collinearity nor heteroscedasticity.

To test hypothesis 5, we measure the standard deviation of price for each of the product types and conditions, and perform an F-test of equality of variances.

\section{Results and Discussion}

The average price of used, remanufactured and new iPod Classics was $\$ 116.7, \$ 167.7$ and $\$ 220.9$, respectively. There were, on average, 1.68 positive keywords per listing, or 1.38, 2.03 and 2.00 for, 
respectively, used, remanufactured and new items. Used iPod Touches fetched, on average, higher prices than remanufactured ones. The prices for the used, remanufactured and new conditions were, respectively, $\$ 181.2, \$ 169.9$ and $\$ 226.3$, and the number of positive keywords per category was 2.20 , 2.78 and 3.33. The average price of used, remanufactured and new iPod Nanos was, respectively, $\$ 68.4, \$ 85.8$ and $\$ 105.1$, and the average number of positive keywords per listing was, respectively, $1.00,2.15$, and 2.58 for used, remanufactured and new iPods. The average number of feedbacks received by sellers trading remanufactured products was also higher than that of the rest because companies, rather than individuals, are engaged in selling remanufactured products. Descriptive statistics are summarized in Tables 3 and 4.

\section{(INCLUDE TABLES 3 AND 4 HERE)}

The results for the regression are shown in Table 5, and the implications for our hypotheses in Table 6. Unsurprisingly, consumers pay more for new items than for remanufactured ones for all three products, controlling for other factors, although for the iPod Nano this effect is not significant. This generally supports H1. Consumers pay a significant premium for remanufactured products relative to used products for all three product types, which supports $\mathrm{H} 2$, an effect that has not been previously documented in the literature.

\section{(INCLUDE TABLES 5 AND 6 HERE)}

This result is important for both sellers and online platforms. Since remanufacturing can increase selling price relative to used items, sellers of remanufactured products should state the condition of the product (e.g. "this product has been tested and refurbished"). In our sample, for 

and $\$ 9$ for the Touch and Nano. This would be an important piece of information for any party deciding between selling used products as-is or incurring the additional expense of remanufacturing them.

Electronic platforms should also acknowledge the importance of such classification, and include remanufactured products as a category of its own. Take the case of eBay, for instance. In the United States, iPods are classified as "used", "refurbished" (i.e. remanufactured) or "new", while in other international eBay platforms, products are classified simply as "used", "new" or "others".

Our results suggest that used, remanufactured and new products are perceived differently by consumers. Remanufactured products are not only less desirable than new products, as others have assumed in prior research on reverse logistics (Atasu et al. 2008, Debo et al. 2005, Oraiopoulos et al. 2009), but they are more desirable than used products.

Regarding hypothesis $\mathrm{H} 3$, we do not find any difference in the effect of positive keywords on the prices paid for remanufactured and new products, in any category of iPod. We also do not find the effect of positive descriptions to be significant for remanufactured or new products. We do find a difference between remanufactured and used products though. The number of positive keywords has a significant (positive) effect on the selling prices of used products, but not of remanufactured ones, for iPod Classic and Nano. This result provides partial support for hypothesis H4. For the iPod Touch, however, we do not find a significant difference in the effect of a positive description across remanufactured and used products. These findings suggest that it can be important for sellers of used items to provide information on the quality of their products, though we would have to speculate why this effect does not appear for the iPod Touch. It may be that the lack of moving parts means that the product is either working or not, and that quality cues therefore 
provide less useful information to consumers than for products with more moving parts and hence more subject to physical wear and tear.

We draw on the theory of information asymmetry and quality cues to explain the effect of such positive descriptions. Used products are perceived as being more heterogeneous in quality than remanufactured or new products, and as a consequence, the market for used products suffers more from information asymmetry. Relevant and effective quality cues, therefore, affect WTP for used products more than they do for remanufactured or new products. Our results might seem to contradict standard signalling theory, because they suggest that sellers can use cues that have no direct or indirect financial consequence to significantly affect perceived quality. Quality cues that are associated with extra costs to bad sellers (e.g. advertisement expenditure) or that are legally binding (e.g. warranties) are considered to affect perceived quality more than those that do not translate in any financial or legal obligation, also known as "cheap talk". However, the fact that buyers can report sellers who misuse such cues, thereby increasing negative feedbacks and hence reducing future cash flows (Lucking-Reiley et al. 2007), discourages sellers from misrepresenting their products.

Regarding H5, we also find empirical evidence in support of this hypothesis. For iPod Classic, the standard deviations of prices of used and remanufactured items are, respectively, 0.45 and 0.16. For iPod Touch, these values are 0.24 and 0.19 . For Nano, we have, respectively, 0.38 and 0.24. The F-test of equality of variances rejects the hypotheses that the variances are the same for used and remanufactured for each of the three types of iPod $(\mathrm{p}<0.05$ for iPod Classic, and $\mathrm{p}<0.01$ for iPod Touch and Nano). This confirms that, for all products, the variance in prices is significantly smaller for remanufactured products than for used products. 


\section{Conclusions, Limitations and Further Research}

In this paper, we empirically investigate the WTP for remanufactured products relative to new and used items using an especially collected dataset of iPods sold on eBay. We find evidence that, while consumers do not consider remanufactured products as perfect substitutes for new ones, remanufacturing does increase consumer WTP relative to used products. This result supports the common assumption of the CLSC literature that consumers expect a discount when buying remanufactured products (Aras et al. 2010, Debo et al. 2005, Mitraa and Webster 2008, Oraiopoulos et al. 2009, Sarvary and Van Wassenhove 2008). This finding may generalize to products that can be brought up to the functional and cosmetic standards of their new counterparts through remanufacturing, but not to products that cannot. This should be the case for most electric appliances, which currently constitute the majority of remanufactured items. Mobile phones, personal computers, MP3-players, digital cameras, and game consoles are some examples of products that are commonly remanufactured. On eBay in the US, $78 \%$ of the refurbished products advertised are in the categories "computer \& networking", "Cell Phones \& PDA", "electronics", "camera \& photo" and "video game". We acknowledge, however, that there may be examples of product categories in which used products are preferred over remanufactured ones, such as perhaps for products that have been broken and cannot be fully repaired to their original conditions. Safetyrelated products may fall into this category, e.g. child car seats.

Furthermore, we analyze whether quality cues, in particular a positive description of the product, has a differential impact on the WTP of used, remanufactured and new products. For two of the three iPod types, quality cues have a stronger impact on consumer WTP for used products than for new or remanufactured products. We explain these patterns drawing on theories of quality 

quality attributes. For sellers of new or remanufactured products this is less important, as our results suggest that quality cues matter little or not at all for these product conditions. For used products, though, each additional positive keyword increases average price by $\$ 8.54$ for the Classic, and by \$3.09 for the Nano. Another implication of our findings for businesses is that, for certain products, remanufacturing a used product can significantly increase its price. We are reluctant to extrapolate too far from our findings. Nevertheless, we believe that the type of analysis executed in this study could help firms to determine whether the potential increase in consumer WTP resulting from upgrading a product from used to remanufactured is sufficient to cover the costs of remanufacturing. For instance, for the iPod Classic, the price difference between remanufactured and used is $\$ 29$, which provides an upper bound for the amount a firm should be willing to spend to remanufacture each item. While the price differential is not the only consideration in deciding whether to remanufacture, it is clearly a key factor, especially for independent remanufacturers who have less or no other strategic considerations to take into account.

Our results do have some inevitable limitations. First, we only consider iPods, and though this is one of the most traded items on eBay, we cannot automatically assume that our findings hold for other types of products. Second, our analysis only examines textual quality cues and one type of visual cue, i.e number of pictures.. Third, our list of keywords, although extensive, cannot cover all possible keywords that can be used to describe a product. Fourth, we do not observe the total volume of sales by each seller, so we cannot correct for that. 
Given the limited research attention paid to marketing of remanufactured products so far, and the complexity of this topic, we believe that yet a number of other factors and the extent to which they affect the prices of remanufactured products need to be further investigated. One question that remains unanswered is whether remanufactured products are sold at a premium because they suffer less from adverse selection (due the fact that they are more homogeneous) or simply because they are perceived as having, on average, higher quality than used products. Laboratory experiments could be used to disentangle these two effects. Another interesting question is whether the type of product sold, e.g. consumer versus commercial product, moderates the differences in prices.

\section{References}

Abbey, J. D., Meloy, M. G., Guide, V. D. R., \& Atalay, S. 2014. Remanufactured Products in ClosedLoop Supply Chains for Consumer Goods. Production and Operations Management. In press (DOI: $10.1111 /$ poms.12238)

Agrawal, B., L.B. Toktay. 2009. Interdisciplinarity in closed-loop supply chain management research. Chapter 12 in Ferguson, M.E. and G.C. Souza, 2010, Closed-Loop Supply Chains: New Developments to Improve the Sustainability of Business Practices, CRC Press, .

Agrawal, V., A. Atasu, and K. van Itterdum. 2010. The effect of remanufacturing on the perceived value of new products. Working paper, Georgia Institute of Technology, College of Management. Aras, N., R. Güllü, and S. Yürülmez, 2010. Optimal inventory and pricing policies for remanufacturable leased products. International Journal of Production Economics 133(1): 262-271.

Archak, N., A. Ghose, and P.G. Ipeirotis. 2011. Deriving the pricing power of product features by mining consumer reviews. Management Science,57(8): 1485-1509.

Akerlof, G.A. 1976. Reply to professor Heal. The Quarterly Journal of Economics, 90 (3), 503. 
Akerlof, G.A. 1970. The market of lemons: quality uncertainty and the market mechanism. The Quarterly Journal of Economics, 90(3), 488-500.

Apple Computers. 2007a. $\quad 100 \quad$ million iPods $\quad$ sold. http://www.apple.com/pr/library/2007/04/09ipod.html (access date: October 2010).

Apple computers. 2007b. Apple store (U.S.) Special deals. 2007. http://store.apple.com (access date: November 2007).

Ariely, D., A. Ockenfels, A.E. Roth. 2005. An experimental analysis of ending rules in internet auctions. RAND Journal of Economics, 36(4), 890-907.

Atasu, A., V.D.R. Guide, and L.N. Van Wassenhove. 2008. Product reuse economics in closed-loop supply chain research. Production and Operations Management, 17(5), 483 - 496.

Bloomberg. 2007. U.S. top selling computer hardware for February 2007. http://www.bloomberg.com/apps/news?pid=conewsstory\&refer=conews\&tkr=AAPL:US\&sid=ag gTRzHFt1Do (access date: October 2010).

Boulding, W., A. Kirmani. 1993. A consumer-side experimental examination of signaling theory: Do consumers perceive warranties as signs of quality? The Journal of Consumer Research, 20(1), 111-123.

Chan, F.T.S., H.K. Chan and J. Vipul. 2012. A framework of reverse logistics for the automobile industry. International Journal of Production Research, 50(5), 1318-1331.

Dawar, N., P. Parker. 1994. Marketing universals: Consumer's use of brand name, price, physical appearance, and retailer reputation as signals of product quality. Journal of Marketing, 58(2), 81-94.

Debo, L. , L. B. Toktay, L.N. Van Wassenhove. 2005. Market segmentation and product technology selection for remanufactured products. Management Science, 51(8), 1193-1205.

Doods, W.B., K.B. Monroe, D. Grewal. 1991. Effects of price, brand and store information on buyer's product evaluation. Journal of Marketing Research, 28(3), 307-319. 
Eaton, D.H. 1995. Valuing information: Evidence from guitar auctions on eBay. Journal of Applied Economics and Policy, 24(1), 1-19.

Farrell, J. 1980. Prices as signals of quality, PhD thesis, University of Oxford, United Kingdom.

Ferguson, M. E., L.B. Toktay. 2006. The effect of competition on recovery strategies. Production and Operations Management, 15(3), 351-368.

Ferrer, G. and J.M. Swaminathan. 2006. Managing new and remanufactured products. Management Science, 52(1), 15-26

Fleischmann, M., J.A.E.E. van Nunen, and B. Grave. 2003. Integrating closed-loop supply chains and spare-parts management at IBM. Interfaces, 33(6), 44-56.

Galbreth, M.R., J.D. Blackburn. 2006. Optimal acquisition and sorting policies for remanufacturing. Production and Operations Management, 15(3), 384-392.

Ghose, A., P. G. Ipeirotis, and A. Sundararajan. 2007. Opinion mining using econometrics: A case Study on reputation systems." Proceedings of the 45th Annual Meeting of the Association of Computational Linguistics. Prague, 416-423.

González-Torre, P., M. Álvarez, J. Sarkis, and B. Adenso-Díaz. 2010. Barriers to the implementation of environmentally oriented reverse logistics: Evidence from the automotive industry sector. British Journal of Management, 21(4), 889-904.

Guide, V.D.R., K. Li. 2010. Market cannibalization of new product sales by remanufactured products. Decision Sciences, 41(3), 547-572.

Harrison, G.W., J.A. List. 2004. Field experiments. Journal of Economic Literature 42 (4), 1009-1055.

Hazen, B. T., Overstreet, R. E., Jones-Farmer, L. A., \& Field, H. S. 2012. The role of ambiguity tolerance in consumer perception of remanufactured products. International Journal of Production Economics, 135(2), 781-790. 
Heijst, D., R. Potharst, and M. van Wezel. 2008. A support system for predicting eBay end prices. Decision Support Systems, 44 (4), 970-982.

HP. 2009. Why buy remanufactured? 2009. http://www.hp.com/united-states/renew/why buy refurbished.html (accessed date: October 2009).

Inderfurth, K., 2004. Optimal policies in hybrid manufacturing/remanufacturing systems with product substitution. International Journal of Production Economics 90(3): 325-343.

iPod history. iPod history. 2010. http://www.ipodhistory.com/ (accessed October 2010).

Kahneman, D., A. Tversky. 1979. Prospect theory: An analysis of decision under risk. Econometrica, 47(2), 263-292.

Katkar, R., D.H. Reiley. 2006. Public versus secret reserve prices in eBay auctions: Results from a pokemon field experiment. The B.E. Journal of Economic Analysis \& Policy, 6(2), 1-23.

Kerr, R., C. Ryan. 2001. Eco-efficiency gains from remanufacturing: A case study of photocopier manufacturing at Fuji Xerox Australia. Journal of Clearner Production, 9(1), 75-81.

Ketzenberg, M. E., Gilvan C. Souza, V.D.R. Guide. 2003. Mixed assembly and disassembly operations for remanufacturing. Production and Operations Management, 12(3). 320-335.

Klaus, M., and C.T. Hendri. 2000. Reverse-logistics strategy for take-back. Interfaces, 30(3), 156-165.

Koppius, O., E. van Heck, M. Wolters. 2004. The importance of product representation online: empirical results and implications for electronic markets. Decision Support Systems 38(3), 161-169.

Krikke, H.R., A. van Harten, and P.C. Schuur. 1999. Business case Océ: Reverse logistic network redesign for copiers. O.R. Spectrum, 21(3), 381-409.

Lee, Z., I. Im, and S.J. Lee. 2000. The effect of negative buyer feedback on prices in internet auction markets. ICIS ' 00 Proceedings of the twenty-first international conference on Information systems, 286-287.

Lewis, G., Asymmetric Information, Adverse Selection and Online Disclosure: The Case of eBay 
Motors. American Economic Review 101 (4), 1535-1546.

Li, J., M. González, and Y. Zhu, 2009. A hybrid simulation optimization method for production planning of dedicated remanufacturing. International Journal of Production Economics 177 (2) (2009): 286301.

Lucking-Reiley, D., D. Brian, N. Prasad, D. Reeves. 2007. Pennies from eBay; The determinants of price in online auctions. The Journal of Industrial Economics, 55(2), 223-233.

Melnik, M., J. Alm. 2002. Does a seller e-commerce reputation matter? Evidence from eBay auctions. Journal of Industrial Economics, 50(3), 337-349.

Milgrom, P. and J. Roberts. 1986. Price and advertising signals of product quality. The Journal of Political Economy, 94(4), 796-821.

Mitraa, S. and S. Webster, 2008. Competition in remanufacturing and the effects of government subsidies. International Journal of Production Economics 111(2): 287-298.

Miyazaki, A.D., D. Grewal, and R.C. Goodstein. 2005. The effect of multiple extrinsic cues on quality perception: a matter of consistency. Journal of Consumer Research, no. 32 (1): 146-153.

Morgan, N. A., \& N. F. Piercy. 1996. Competitive Advantage, Quality Strategy and the Role of Marketing. British Journal of Management, 7(3), 231-245.

Muller, R.A., S. Mestelman. 1994. Emission trading with shares and coupons: A laboratory experiment. The Energy Journal 15(2), 195-211.

Oraiopoulos, N., M.E. Ferguson, L.B. Toktay. Relicensing as a secondary market strategy. Working paper, Georgia Institute of Technology, College of Management, 2009.

Ovchinnikov, A. Revenue and Cost Management for Remanufactured Products. 2011. Production and Operations Management (early view), doi: 10.1111/j.1937-5956.2010.01214.x

Parlikad, A.K., D. MacFarlane. 2007. RFID-based product information in end-of-life decision making. Control Engineering Practive 15(11), 1348-1363. 
Prahinskia, C., C. Kocabasoglub. 2006. Empirical research opportunities in reverse supply chains. Omega, The International Journal of Management Science, 34(6), 519-532.

Quariguasi Frota Neto, J. 2008. Eco-efficient Supply Chains for Electrical and Electronic Products. Ph.D. thesis, Rotterdam School of Management, Erasmus University, The Netherlands.

Ramachandran, V., S. Viswanathan, S. Gosain. 2008. The impact of online information on the purchase of certified used cars. Working paper, Robert W. Smith School School of Business, University of Maryland.

Resnick, P., R. Zeckhauser, J. Swanson, K. Lockwoos. 2006. The value of reputation on eBay: A controlled experiment. Experimental Economics, 9(2), 79-101.

Rubio, S., A. Chamorro, and F.J. Miranda. 2008. Characteristics of research on reverse logistics. International Journal of Production Research, 46(4), 1099-1120.

Savaskan, R.C., S. Bhattacharya, and L.N. Van Wassenhove. 2004. Closed-loop supply models with product remanufacturing. Management Science, 50(2), 239-252.

Srivastava, J., and A. Mitra. 1998. Warranty as a signal of quality: The moderating effect of consumer knowledge and quality evaluations. Marketing Letters, 9(4), 327-336.

Subramanian, R., and R. Subramanyam. 2012. Key drivers in the market of remanufactured products. Manufacturing \& Service Operations Management, 14(2), 315-326.

Tang, O., R. Teunter. 2007. Economic lot scheduling problem with returns. Production and Operations Management, 15(4), 488-497.

Thierry, M., M. Salomon, J.A.E.E. van Nunen, L.N. Van Wassenhove. 1995. Strategic Issues in Product Recovery Management. California Management Review, 37(2), 114-135.

Van Wassenhove, L.N. and C. Zikopoulos. 2010. On the effect of quality overestimation in remanufacturing. International Journal of Production Research, 48(18), 5263-5280.

White, H.. 1980. A heteroskedasticity-consistent covariance matrix estimator. Econometrica, 48(4), 
817-838.

Wiggins, S.N., and L.W. Lane. 1983. Quality uncertainty, search and advertising. American Economic Review, 73(5), 881-889. 
Table 1. Launch dates for Apple iPod versions used in this paper

\begin{tabular}{ccc}
\hline iPod model & Release date & Models \\
\hline Classic & October 2001 & 6 \\
Touch & January 2005 & 4 \\
Nano & September 2005 & 6 \\
\hline
\end{tabular}

Note: the iPod Classic was first released under the name iPod (without model specification). Source: iPod history (http://www.ipodhistory.com/), accessed July 2010.

Table 2. Examples of favorable item descriptions

The item in this auction is in Grade A condition.

$100 \%$ guaranteed in excellent working condition or your money back!

100\% Functional, 100\% Brand New.

Like new condition!

This iPod works perfectly, has had very little use, and is in truly excellent condition!

$80 \mathrm{~Gb}$ iPod Classic 5 Generation is very lightly used, in great condition!

Note: This item is in excellent condition.

Note: Examples of positive descriptions included in the eBay listing analysed. The highlighted text is coded into variable POSKEYWORD. For the fifth sentence, for instance, the software agent finds "works perfectly" and "excellent condition" and sets POSKEYWORDS=2. The software searches all text visible to the consumer. The software agent identifies the following items: "as new, like new, brand new, few scratches, barely used, mint, good condition, great condition, hardly used, genuine, excellent condition, original box, immaculate, sealed, working condition, never used, almost new, perfect condition, spanking new condition, nearly new, great cosmetic condition, like new condition, works perfectly". 
Table 3. Number of used, remanufactured and new products in the sample

\begin{tabular}{|c|c|c|c|c|c|c|c|c|c|}
\hline Item (iPods) & & Classic & & & Touch & & & Nano & \\
\hline No. of observations & & 1,500 & & & 1,700 & & & 1,500 & \\
\hline No. of observations used & & 632 & & & 541 & & & 543 & \\
\hline Product condition & used & rem. & New & used & rem. & new & used & Rem & new \\
\hline No. of observations used & 410 & 110 & 112 & 206 & 129 & 206 & 216 & 157 & 170 \\
\hline Average price & $\$ 116.7$ & $\$ 166.7$ & $\$ 220.9$ & $\$ 181.2$ & $\$ 169.9$ & $\$ 226.3$ & $\$ 68.4$ & $\$ 85.4$ & $\$ 105.1$ \\
\hline
\end{tabular}

Note: Number of observations and average prices for iPods Classic, Touch and Nano.

Table 4. Descriptive statistics

\begin{tabular}{|c|c|c|c|c|c|c|c|c|c|c|c|c|c|c|c|}
\hline \multirow[t]{2}{*}{ Variable } & \multicolumn{5}{|c|}{ iPod Classic } & \multicolumn{5}{|c|}{ iPod Touch } & \multicolumn{5}{|c|}{ iPod Nano } \\
\hline & Mean & Median & St. Dev. & Min & Max & Mean & Median & St. Dev. & Min & Max & Mean & Median & St. Dev. & Min & Max \\
\hline PRICE & 135.5 & 143.90 & 64.60 & 10.40 & 425.00 & 195.6 & 183.5 & 51.47 & 100.0 & 371.1 & 84.59 & 82.99 & 29.98 & 4.990 & 240,00 \\
\hline \multicolumn{16}{|l|}{ ORIGINAL } \\
\hline PICTURE & 1.032 & 0.000 & 1.520 & 0.000 & 12.00 & 1.141 & 0.000 & 1.749 & 0.000 & 13.00 & 0.5885 & 0.000 & 1.1046 & 0.000 & 9.000 \\
\hline POSKEYWORD & 1.513 & 1.000 & 1.782 & 0.000 & 12.00 & 2.695 & 1.000 & 3.395 & 0.000 & 14.00 & 1.825 & 2.000 & 1.776 & 0.000 & 9.000 \\
\hline POSFEEDBACK & 55769 & 95.00 & 11913 & 0.000 & 38090 & 4582 & 128.0 & 8903 & 0.000 & 63640 & 6071 & 164.0 & 12,88 & 0.000 & 69,280 \\
\hline NEGFEEDBACK & 18.88 & 0.000 & 44.56 & 0.000 & 669.0 & 44.04 & 1.000 & 134.2 & 0.000 & 923.0 & 41.90 & 1.000 & 155.0 & 0.000 & 1,349 \\
\hline MEMORY & 88.48 & 80.00 & 44.10 & 1.000 & 160.0 & 14.14 & 8.000 & 8.548 & 0.005 & 32.00 & 7.018 & 8.000 & 4.480 & 0.000 & 80.00 \\
\hline GENERATION & 5.198 & 6.000 & 1.624 & 0.000 & 7.000 & 1.360 & 2.000 & 0.796 & 0.000 & 3.00 & 2.562 & 3.000 & 1.503 & 0.000 & 6.000 \\
\hline SHIP & 3.885 & 0.000 & 5.081 & 0.000 & 30.00 & 4.145 & 0.000 & 13.91 & 0.000 & 300.0 & 3.654 & 0.000 & 4.614 & 0.000 & 19.99 \\
\hline
\end{tabular}


Table 5. OLS regression of sale prices of new and used items relative to remanufactured items

\begin{tabular}{|c|c|c|c|}
\hline Variable/Product & iPod Classic & iPod Touch & iPod Nano \\
\hline \multirow[t]{2}{*}{ (Intercept) } & $38.68 * * *$ & $76.78 * * *$ & $36.68 * * *$ \\
\hline & $(0.000)$ & $(0.000)$ & $(0.000)$ \\
\hline \multirow[t]{2}{*}{ POSKEYWORD } & -2.706 & 0.065 & -0.899 \\
\hline & $(0.269)$ & $(0.911)$ & $(0.180)$ \\
\hline \multirow[t]{2}{*}{ ORIGINAL.PICTURE } & -1.800 & -4.940 & -0.536 \\
\hline & $(0.438)$ & $(0.084)$ & $(0.841)$ \\
\hline \multirow[t]{2}{*}{ CONDITION=NEW } & $36.69 * * *$ & $30.85 * * *$ & 5.982 \\
\hline & $(0.000)$ & $(0.000)$ & $(0.116)$ \\
\hline \multirow[t]{2}{*}{ CONDITION=USED } & $-29.30 * * *$ & $-9.114 *$ & $-9.599 * *$ \\
\hline & $(0.000)$ & $(0.084)$ & $(0.004)$ \\
\hline \multirow[t]{2}{*}{ POSFEEDBACK } & 0.000 & $-0.001 * *$ & 0.932 \\
\hline & $(0.864)$ & $(0.028)$ & $(0.000)$ \\
\hline \multirow[t]{2}{*}{ NEGFEEDBACK } & -0.002 & 0.032 & $0.001 * *$ \\
\hline & $(0.682)$ & $(0.277)$ & $(0.040)$ \\
\hline \multirow[t]{2}{*}{ MEMORY } & $0.974 * * *$ & $4.489 * * *$ & $1.692 * * *$ \\
\hline & $(0.000)$ & $(0.000)$ & $(0.000)$ \\
\hline \multirow[t]{2}{*}{ GENERATION } & $4.662 * * *$ & $30.06^{* * *}$ & $14.02 * * *$ \\
\hline & $(0.000)$ & $(0.000)$ & $(0.000)$ \\
\hline \multirow[t]{2}{*}{ SHIP } & -5.681 & -0.068 & $-2.149 * * *$ \\
\hline & $(0.010)^{* *}$ & $(0.399)$ & $(0.000)$ \\
\hline \multirow[t]{2}{*}{$(\mathrm{CONDITION}=\mathrm{NEW}) * \mathrm{POSWORD}$} & 2.936 & -0.069 & 0.387 \\
\hline & $(0.274)$ & $(0.930)$ & $(0.705)$ \\
\hline \multirow[t]{2}{*}{$(\mathrm{CONDITION}=\mathrm{USED}) * \mathrm{POSWORD}$} & $8.539 * *$ & -0.346 & $3.087 * *$ \\
\hline & $(0.001)$ & $(0.698)$ & $(0.015)$ \\
\hline \multirow[t]{2}{*}{ (CONDITION=NEW)*ORIGINAL.PICTURE } & $14.17 * * *$ & 2.731 & 4.011 \\
\hline & $(0.000)$ & $(0.418)$ & $(0.193)$ \\
\hline \multirow[t]{2}{*}{$(\mathrm{CONDITION=USED}) *$ ORIGINAL.PICTURE } & $5.614 * *$ & 6.354 & 1.474 \\
\hline & $(0.021)$ & $(0.418)$ & $(0.607)$ \\
\hline R-squared & 0.84 & 0.80 & 0.71 \\
\hline R-squared with control variables only & 0.71 & 0.71 & 0.67 \\
\hline $\mathrm{N}$ & 693 & 542 & 542 \\
\hline
\end{tabular}

Note: The table shows the coefficients and associated p-values (between brackets) for the OLS regression analyzing the price of new and used items relative to remanufactured for the three product types.

$*$ denotes significance at $\mathrm{p}<0.10, * *$ at $\mathrm{p}<0.05, * * *$ at $\mathrm{p}<0.01$, and the $\mathrm{p}$-values reported are for twotailed tests of significance. All values are presented with 4 significant digits. 
Table 6. Results for hypotheses H1, H2, H3 and H4.

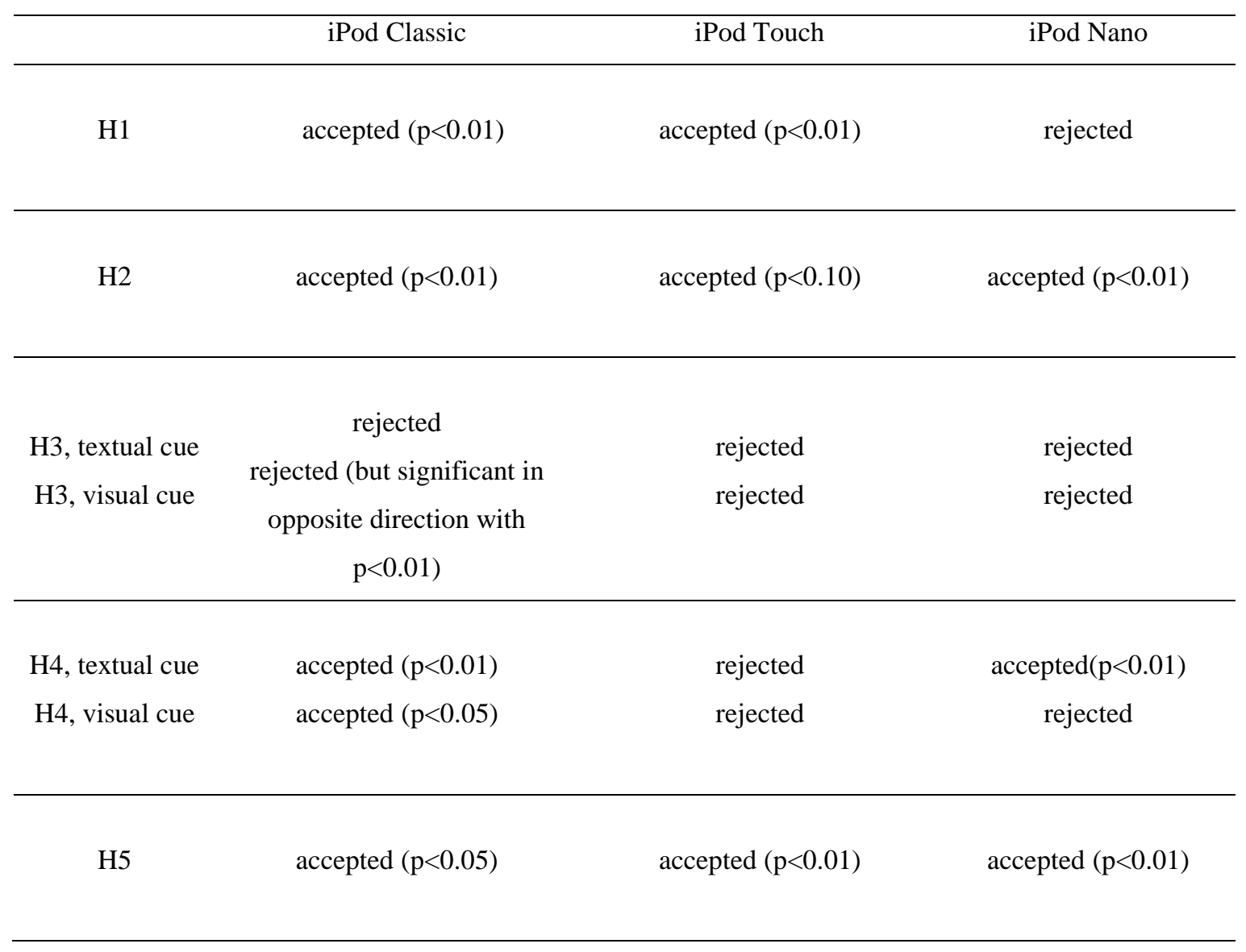

Note: The p-values reported are for two-tailed tests of significance. The hypotheses tested are as follows. H1. Selling prices of new products are, ceteris paribus, higher than those of remanufactured products.

H2. Selling prices of remanufactured products are, ceteris paribus, higher than those of used products. H3. Selling prices of remanufactured products are, ceteris paribus, more affected by quality cues than those of new products.

H4. Selling prices of remanufactured products are, ceteris paribus, less affected by quality cues than those of used products.

H5. There is less variability in sales prices for remanufactured products than there is for used products.

(Note that we follow common convention by reporting p-values for the two-tailed test that the corresponding coefficient is different from zero, not for the one-tailed test of each specific hypothesis.) 
Table 7. Correlation Matrix for iPod Classic

\begin{tabular}{|c|c|c|c|c|c|c|c|c|c|}
\hline & POSKEYWORD & ORIGINAL.PICTURE & CONDITION=NEW & CONDITION=USED & POSFEEDBACK & NEGFEEDBACK & MEMORY & GENERATION & SHIP \\
\hline POSKEYWORD & 1.00 & & & & & & & & \\
\hline ORIGINAL.PICTURE & -0.04 & 1.00 & & & & & & & \\
\hline CONDITION=NEW & 0.16 & -0.15 & 1.00 & & & & & & \\
\hline CONDITION=USED & -0.23 & 0.27 & -0.63 & 1.00 & & & & & \\
\hline POSFEEDBACK & 0.12 & -0.23 & -0.12 & -0.37 & 1.00 & & & & \\
\hline NEGFEEDBACK & 0.09 & -0.12 & -0.09 & -0.18 & 0.67 & 1.00 & & & \\
\hline MEMORY & 0.16 & -0.28 & 0.29 & -0.42 & 0.28 & 0.14 & 1.00 & & \\
\hline GENERATION & -0.01 & -0.18 & 0.02 & -0.13 & 0.16 & 0.00 & 0.44 & 1.00 & \\
\hline SHIP & -0.12 & 0.20 & 0.01 & 0.18 & -0.30 & -0.20 & -0.19 & -0.18 & 1.00 \\
\hline
\end{tabular}

Table 8. Correlation Matrix for iPod Touch

\begin{tabular}{|c|c|c|c|c|c|c|c|c|c|}
\hline & POSKEYWORD & ORIGINAL.PICTURE & CONDITION=NEW & CONDITION=USED & POSFEEDBACK & NEGFEEDBACK & MEMORY & GENERATION & SHIP \\
\hline POSKEYWORD & 1.00 & & & & & & & & \\
\hline ORIGINAL.PICTURE & -0.09 & 1.00 & & & & & & & \\
\hline CONDITION=NEW & 0.02 & -0.09 & 1.00 & & & & & & \\
\hline CONDITION=USED & -0.11 & 0.40 & -0.61 & 1.00 & & & & & \\
\hline POSFEEDBACK & 0.07 & -0.30 & -0.22 & -0.13 & 1.00 & & & & \\
\hline NEGFEEDBACK & 0.04 & -0.20 & -0.16 & 0.06 & 0.90 & 1.00 & & & \\
\hline MEMORY & 0.01 & 0.01 & 0.08 & 0.10 & -0.15 & -0.07 & 1.00 & & \\
\hline GENERATION & -0.03 & -0.13 & 0.17 & -0.26 & -0.14 & -0.24 & -0.08 & 1.00 & \\
\hline SHIP & -0.05 & 0.11 & 0.00 & 0.12 & -0.08 & -0.03 & 0.15 & -0.05 & 1.00 \\
\hline
\end{tabular}

Table 9. Correlation Matrix for iPod Nano

\begin{tabular}{|c|c|c|c|c|c|c|c|c|c|}
\hline & POSKEYWORD & ORIGINAL.PICTURE & CONDITION=NEW & CONDITION=USED & POSFEEDBACK & NEGFEEDBACK & MEMORY & GENERATION & SHIP \\
\hline POSKEYWORD & 1.00 & & & & & & & & \\
\hline ORIGINAL.PICTURE & -0.20 & 1.00 & & & & & & & \\
\hline CONDITION=NEW & 0.12 & -0.08 & 1.00 & & & & & & \\
\hline CONDITION=USED & -0.38 & 0.37 & -0.52 & 1.00 & & & & & \\
\hline POSFEEDBACK & 0.09 & -0.17 & -0.25 & -0.21 & 1.00 & & & & \\
\hline NEGFEEDBACK & 0.03 & -0.11 & -0.16 & -0.04 & 0.78 & 1.00 & & & \\
\hline MEMORY & 0.09 & 0.02 & 0.20 & -0.11 & -0.05 & -0.09 & 1.00 & & \\
\hline GENERATION & 0.26 & -0.17 & 0.18 & -0.33 & 0.20 & -0.01 & 0.19 & 1.00 & \\
\hline SHIP & -0.29 & 0.14 & 0.04 & 0.30 & -0.24 & -0.14 & 0.01 & -0.11 & 1.00 \\
\hline
\end{tabular}

